\title{
The effects of the Cox maze procedure on atrial function
}

Rochus K. Voeller, MD, Andreas Zierer, MD, Shelly C. Lall, MD, Shun-ichiro Sakamoto, MD, Nai-Lun Chang, BS, Richard B. Schuessler, PhD, Marc R. Moon, MD, and Ralph J. Damiano, Jr, MD

Objective: The effects of the Cox maze procedure on atrial function remain poorly defined. The purpose of this study was to investigate the effects of a modified Cox maze procedure on left and right atrial function in a porcine model.

\begin{abstract}
Methods: After cardiac magnetic resonance imaging, 6 pigs underwent pericardiotomy (sham group), and 6 pigs underwent a modified Cox maze procedure (maze group) with bipolar radiofrequency ablation. The maze group had preablation and immediate postablation left and right atrial pressure-volume relations measured with conductance catheters. All pigs survived for 30 days. Magnetic resonance imaging was then repeated for both groups, and conductance catheter measurements were repeated for the right atrium in the maze group.
\end{abstract}

Results: Both groups had significantly higher left atrial volumes postoperatively. Magnetic resonance imagingderived reservoir and booster pump functional parameters were reduced postoperatively for both groups, but there was no difference in these parameters between the groups. The maze group had significantly higher reduction in the medial and lateral left atrial wall contraction postoperatively. There was no change in immediate left atrial elastance or in the early and 30-day right atrial elastance after the Cox maze procedure. Although the initial left atrial stiffness increased after ablation, right atrial diastolic stiffness did not change initially or at 30 days.

Conclusions: Performing a pericardiotomy alone had a significant effect on atrial function that can be quantified by means of magnetic resonance imaging. The effects of the Cox maze procedure on left atrial function could only be detected by analyzing segmental wall motion. Understanding the precise physiologic effects of the Cox maze procedure on atrial function will help in developing less-damaging lesion sets for the surgical treatment of atrial fibrillation.

\section{Supplemental material is available online.}

Over the last 2 decades, the Cox maze procedure has remained the gold standard for the surgical treatment of atrial fibrillation (AF). ${ }^{1}$ The final iteration of this procedure was termed the Cox maze III procedure. It offered the first successful surgical treatment for patients with medically refractory AF. Although this cut-and-sew Cox maze procedure had excellent results, with long-term cure rates of well over $90 \%$, it was not widely adopted by most cardiac surgeons because of its technical complexity, invasiveness, and associated morbidity. ${ }^{2}$

The introduction of surgical ablation technology has dramatically changed the field of AF surgery. ${ }^{3,4}$ Centers around

\footnotetext{
From the Division of Cardiothoracic Surgery, Washington University School of Medicine, Barnes-Jewish Hospital, St Louis, Mo.

Ralph Damiano reports consulting fees from Atricure, Medtronic, and Medical CV; lecture fees from Atricure and Cryotech, and grant support from Atricure. Marc Moon reports lecture fees from Edwards. Richard Schuessler reports consulting fees from Atricure and Medtronic, and grant support from Atricure and Estech.

This study was supported by the National Institutes of Health grants R01 HL03225721 and F32 HL082129-02.

Received for publication Nov 24, 2007; accepted for publication Jan 24, 2008.

Address for reprints: Ralph J. Damiano, Jr, MD, Washington University School of Medicine, Barnes-Jewish Hospital, Suite 3108 Queeny Tower, 1 Barnes-Jewish Hospital Plaza, St. Louis, MO 63110 (E-mail: damianor@wustl.edu).

J Thorac Cardiovasc Surg 2008;136:1257-64

0022-5223/\$34.00

Copyright (c) 2008 by The American Association for Thoracic Surgery

doi:10.1016/j.jtcvs.2008.01.053
}

the world have replaced the classic surgical incisions of the Cox maze procedure with ablation lines on the atria using various energy sources. This has simplified the operation and made it more accessible to cardiac surgeons around the world. After extensive investigation, our laboratory has shown that bipolar radiofrequency (RF) ablation can safely create reliable transmural lesions and be used to replace most of the surgical incisions of the original cut-and-sew Cox maze III procedure. ${ }^{5-7}$

A bipolar RF ablation-assisted Cox maze procedure, termed the Cox maze IV procedure, has been used exclusively at our institution since 2002. Early and midterm clinical experiences with the Cox maze IV procedure have shown excellent results, with significantly shorter cardiopulmonary bypass and crossclamp times. ${ }^{8-12}$ A recent propensity analysis performed by our group on patients who underwent the Cox maze III versus Cox maze IV procedures found no difference in freedom from AF recurrence at 1 year. ${ }^{13}$

Despite the clinical success of the Cox maze procedure in restoring sinus rhythm, the procedure has been shown in previous studies with echocardiography to have a negative effect on atrial function. ${ }^{14,15}$ However, there has not been any comprehensive experimental investigation of the effect of the Cox maze procedure on the right atrium (RA) and left atrium (LA) by using a more sophisticated and load-independent methodology. Regional wall motion has not been examined, despite the fact that the multiple incisions or ablation lines cross, isolate, or both large areas of the RA and LA. With the rapidly increasing popularity of surgical 


\begin{tabular}{|c|c|}
\hline \multicolumn{2}{|c|}{ Abbreviations and Acronyms } \\
\hline $\mathrm{AF}$ & $=$ atrial fibrillation \\
\hline BSA & $=$ body surface area \\
\hline LA & $=$ left atrium \\
\hline LAA & $=$ left atrial appendage \\
\hline $\mathrm{LA}_{\mathrm{AE}}$ & $\begin{aligned}= & \text { left atrial active emptying percentage } \\
& \text { of total emptying }\end{aligned}$ \\
\hline $\mathrm{LA}_{\mathrm{AEI}}$ & $=$ left atrial active emptying index \\
\hline $\mathrm{LA}_{\mathrm{CC}}$ & $=$ left atrial volume change \\
\hline $\mathrm{LA}_{\mathrm{EF}}$ & $=$ left atrial active ejection fraction \\
\hline $\mathrm{LA}_{\mathrm{EI}}$ & $=$ left atrial active emptying index \\
\hline $\mathrm{LA}_{\max }$ & $=$ maximal left atrial volume \\
\hline $\mathrm{LA}_{\min }$ & $=$ minimal left atrial volume \\
\hline $\mathrm{LA}_{\mathrm{PE}}$ & $\begin{array}{l}=\text { left atrial passive percentage of total } \\
\text { emptying }\end{array}$ \\
\hline $\mathrm{LA}_{\mathrm{PEI}}$ & $=$ left atrial passive emptying index \\
\hline LAPTE $_{\text {PTE }}$ & $=$ left atrial percentage total emptying \\
\hline $\mathrm{LA}_{\text {rel max }}$ & $=$ relative maximal left atrial volume \\
\hline $\mathrm{LA}_{\text {rel min }}$ & $=$ relative minimal left atrial volume \\
\hline LV & $=$ left ventricular \\
\hline LVSV & $=$ left ventricular stroke volume \\
\hline MRI & $=$ magnetic resonance imaging \\
\hline PV & $=$ pulmonary vein \\
\hline RA & $=$ right atrium \\
\hline $\mathrm{RF}$ & $=$ radiofrequency \\
\hline
\end{tabular}

intervention for $\mathrm{AF}$, a better understanding of the effects of the Cox maze procedure on atrial function is urgently needed. This would have important implications regarding decisions to discontinue anticoagulation and might guide future development of less invasive surgical strategies.

The purpose of this study was to investigate the acute and chronic effects of the Cox maze procedure on atrial function in a chronic porcine model. Cardiac magnetic resonance imaging (MRI) was used to noninvasively assess global and regional LA function. In addition, conductance catheters were used to measure the dynamic atrial elastance and stiffness, as derived from pressure-volume relationships. A unique aspect of this study was the use of a sham group to control for the functional effects of pericardiotomy alone.

\section{MATERIALS AND METHODS \\ Experimental Protocol}

Twelve domestic pigs weighing 60 to $75 \mathrm{~kg}$ were used in this study. All animals received humane care in compliance with the "Guide for the care and use of laboratory animals" published by the National Institutes of Health (National Institutes of Health publication no. 85-23, revised 1985). The study was also approved by the Washington University School of Medicine Animal Studies Committee. A baseline cardiac MRI was obtained from each pig after achievement of general anesthesia. After this MRI, pigs were given at least 2 days to recover from anesthesia before undergoing surgical intervention.
The animals were divided into 2 groups. The sham group included 6 pigs that underwent median sternotomy and pericardiotomy only. This was done as a control for the study because in previous studies pericardiotomy has been shown to have a significant effect on atrial function. The second group, the maze group, included 6 pigs that underwent a modified Cox maze procedure.

After the baseline MRI, each pig in the maze group $(n=6)$ underwent a modified Cox maze procedure on the beating heart without cardiopulmonary bypass, as previously described (Figure 1). ${ }^{6}$ The animals were premedicated, intubated, and anesthetized with $2 \%$ to $4 \%$ isoflurane and were continuously monitored. Median sternotomy was performed, and the heart was exposed through a pericardiotomy after administering amiodarone (150-mg bolus administered intravenously) to prevent arrhythmias.

The pigs were fully heparinized ( $350 \mathrm{U} / \mathrm{kg}$ administered intravenously), and the activated clotting time was maintained at greater than 250 seconds. By using conductance catheters, preablation pressure-volume relationships were sequentially measured for the RA and LA, as described below. The modified Cox maze ablation set was then performed. Immediate electrical isolation was documented by pacing just distal to the ablation lines at the right and left pulmonary veins (PVs) and at the LA appendage (LAA) at a stimulus strength of $20 \mathrm{~mA}$. Conductance catheter measurements were then repeated for both atria immediately after the ablations. The pericardium was closed, and the sternum was reapproximated. The animals were closely monitored for 48 hours and kept alive for 30 days. Daily aspirin, $81 \mathrm{mg}$ administered orally, was given, beginning on the first day after the operation. No antiarrhythmic drugs were administered during this period.

At 30 days postoperatively, all animals in both groups underwent a follow-up cardiac MRI study to assess the chronic changes in LA function. Immediately after the MRI, each animal underwent redo median sternotomy. The animals were given full heparinization again, and conductance catheter measurements were taken for the RA for the maze group. Conductance catheter measurements were not taken for the LA for the maze group because accurate inflows could not be quantified, as with the RA, which is required for calibrating the pressure-volume relations. Chronic electrical isolation was confirmed by failure to capture by means of epicardial pacing (20 $\mathrm{mA}$ and 5-ms pulse duration) of the right and left PVs and the LAA distal to the ablation lines. Finally, AF induction was attempted in both groups by means of 2 trials of rapid pacing from the RA free wall for 30 seconds ( $20 \mathrm{~mA}, 400 \mathrm{~ms}$, and 150 beats/min). If unsuccessful, 2 trails of burst pacing were performed from the RA free wall with $8 \mathrm{~S} 1$ at a cycle length of $150 \mathrm{~ms}$, followed by a single extra stimulus $\mathrm{S} 2$ of $90 \mathrm{~ms}$. If still unsuccessful, $2.5 \mathrm{mg}$ of neostigmine administered intravenously was given as a bolus, and the rapid pacing protocol was repeated, followed by burst pacing. At the conclusion of the study, the animal was killed, and the heart was removed en bloc for histologic assessment.

\section{Modified Cox Maze Procedure}

The modified Cox maze procedure performed in the maze group represented all of the atrial lesions in the Cox maze IV procedure used clinically (Figure 1). All lesions were performed without cardiopulmonary bypass by using bipolar RF ablation, as described in a previous publication. ${ }^{5-7}$

\section{Bipolar RF Ablation Device}

The bipolar RF ablation system, Atricure Isolator II (Atricure, Inc, Cincinnati, Ohio), was comprised of an ablation clamp and an ablation and sensing unit. The clamp consisted of 2 jaws in parallel with opposing electrodes clamped on target tissue during ablation. Energy was delivered from the ablation and sensing unit to the instrument by using an algorithm based on the assessment of tissue conductance every $10 \mathrm{~Hz} .{ }^{5,6}$ Full-thickness ablation was determined when the tissue conductance decreased to a specified level and remained there for 3 seconds. A laptop computer was used to collect the time, current, voltage, impedance, conductance, energy, power, and temperature in real time. The temperature was recorded by using a thermocouple located $1 \mathrm{~mm}$ from the edge of the electrode in the jaw of the clamp device. 


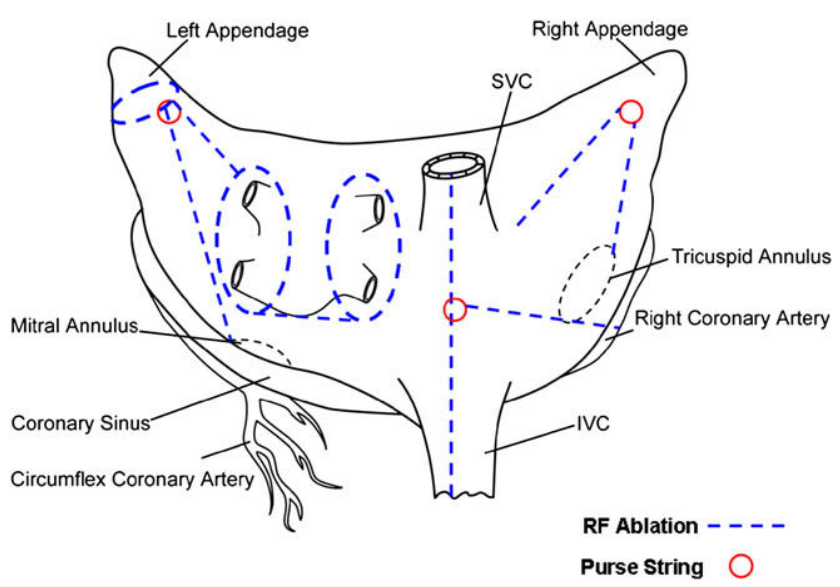

FIGURE 1. The modified Cox maze procedure lesion set. All lesions were created off cardiopulmonary bypass with the Atricure Isolator II bipolar radiofrequency ablation device. $S V C$, Superior vena cava; $I V C$, inferior vena cava; $R F$, radiofrequency.

\section{MRI}

The cardiac MRI protocol used in this study has been previously described in detail. ${ }^{16}$ Briefly, each animal was placed in a clinical $1.5-\mathrm{T}$ MRI scanner (Philips Medical Systems, Andover, Mass) in a supine position. Multiple anatomic and functional cine images of the heart were obtained by using the retrospectively gated breath-hold balanced turbo field echocardiographic method with parallel imaging. High-resolution cine loops of the horizontal long axis, left ventricular (LV) outflow tract, and short-axis stacks $8 \mathrm{~mm}$ apart were obtained during multiple breath-hold sequential runs. Velocity-encoded images perpendicular across the mitral and tricuspid annuli were obtained to quantify flows and to evaluate for any regurgitation. Coronary artery anatomy and patency were assessed by using a navigator-gated, free-breathing, T2-weighted prepared turbo field echocardiographic acquisition, as described by Botnar and colleagues. ${ }^{17}$

By using the short-axis stack images, instantaneous LA volume versus cardiac cycle and LV volume versus cardiac cycle curves were generated. ${ }^{16}$ Figure E1 represents a typical LA and LV volume curve during a full cardiac cycle. Point A represents the minimal LA volume $\left(\mathrm{LA}_{\min }\right)$ at end-ventricular diastole. At end-ventricular systole, the LA reaches point $\mathrm{B}$, the maximal volume $\left(\mathrm{LA}_{\mathrm{max}}\right)$. Point $\mathrm{C}$ refers to the middiastolic relative $\mathrm{LA}$ minimal volume $\left(\mathrm{LA}_{\text {rel min }}\right)$ at the end of rapid passive LA emptying. Point $\mathrm{D}$ is the relative maximal $\mathrm{LA}$ volume $\left(\mathrm{LA}_{\mathrm{rel} \mathrm{max}}\right)$ immediately before atrial systole. The $\mathrm{LV}$ end-diastolic volume (point E) and end-systolic volume (point F) were used to calculate LV stroke volume (LVSV) and LV ejection fraction.

Global LA function was characterized by calculating the reservoir, conduit, and booster pump volumes and their percentage contribution to $L V$ filling. LA reservoir volume was defined as $\mathrm{LA}_{\max }-\mathrm{LA}_{\text {rel min }}$ (point $\mathrm{B}-$ point C). LA booster pump volume (LABPV) was defined as $\mathrm{LA}_{\text {rel max }}-\mathrm{LA}_{\text {min }}$ (point $\mathrm{D}$ - point A). LA conduit volume ( $\mathrm{LACV}$ ) was calculated by using the following equation:

$L V S V=L A B P V+L A R V+L A V C V$.

Various parameters for the reservoir, conduit, and booster pump functions of the LA were also derived, as previously described by Järvinen and associates $^{18}$ and Spencer and coworkers. ${ }^{19}$ Cyclical LA volume change $\left(\mathrm{LA}_{\mathrm{CC}}\right)$ was defined as $\mathrm{LA}_{\max }-\mathrm{LA}_{\min }$ (point $\mathrm{B}$ - point $\mathrm{A}$ ). The following parameters were calculated by using equations based on volume ratios during various time points of the LA volume curve:

$L A$ percentage total emptying $(L A P T E)=\left(L A_{\max }-L A_{\min }\right) / L A_{\max } \times 100$

$$
\begin{aligned}
& L A \text { expansion index }(L A E I)=\left(L A_{\max }-L A_{\min }\right) / L A_{\min } \times 100 \\
& L A \text { active ejection fraction }(L A E F)=\left(L A_{\text {rel } \max }-L A_{\min }\right) / L A_{\max } \times 100
\end{aligned}
$$

$L A$ passive emptying percentage of total emptying ( $L A P E)$

$$
=\left(L A_{\max }-L A_{\text {rel } \max }\right) /\left(L A_{\max }-L A_{\min }\right) \times 100
$$

$L A$ passive emptying index $(L A P E I)=\left(L A_{\max }-L A_{\text {rel } \max }\right) / L A_{\max } \times 100$

$L A$ active emptying percentage of total emptying ( $L A A E)$

$$
=\left(L A_{\text {rel } \max }-L A_{\min }\right) /\left(L A_{\max }-L A_{\min }\right) \times 100
$$

$L A$ active emptying index $(L A A E I)=\left(L A_{\text {rel } \max }-L A_{\min }\right) / L A_{\text {rel } \max } \times 100$

LA reservoir function parameters included $\mathrm{LA}_{\mathrm{CC}}, \mathrm{LA}_{\mathrm{EI}}$, and $\mathrm{LA}_{\mathrm{PTE}}$; $\mathrm{LA}$ conduit function parameters included $\mathrm{LA}_{\mathrm{PE}}$ and $\mathrm{LA}_{\mathrm{PEI}}$; and $\mathrm{LA}_{\mathrm{EF}}, \mathrm{LA}_{\mathrm{AE}}$, and $\mathrm{LA}_{\mathrm{AEI}}$ represented LA booster pump function.

Regional LA function was characterized by quantifying the segmental LA wall motion with cine MRI. The LA wall was divided into 4 segments: anterior, posterior, medial, and lateral segments (Figure E2). The percentage shortening of $4 \mathrm{LA}$ wall segments was quantified by measuring the difference in the distance between the superior dome of the LA, which is stationary during the cardiac cycle, and the corresponding position on the mitral annulus during atrial systole and diastole. The horizontal long-axis cine MRI was used to visualize and quantify the medial and lateral LA wall segmental motion; the LV outflow tract cine MRI was used to quantify the anterior and posterior LA wall segmental motion.

\section{Conductance Catheter Measurements}

Placement of conductance catheters. First, ultrasonic flow probes (10-12 mm perivascular probes with a T206 Flowmeter; Transonic Systems, Ithaca, NY) were placed around the superior vena cava and inferior vena cava approximately $1 \mathrm{~cm}$ from the caval-atrial junction to obtain accurate measurement of RA inflow. Through a small purse-string suture at the base of the RA appendage, a 5F combined pressure-volume conductance catheter (Millar SPR-766; Millar Instruments, Inc, Houston, Tex) was introduced and positioned along the long axis of the RA, so that the tip of the catheter rested at the RA-inferior vena caval junction (Figure E3). ${ }^{20}$ The conductance catheter was then connected to the signal conditioner processor (Sigma 5DF; CD Leycom, Zoetermeer, The Netherlands). ${ }^{21}$ After completion of RA pressure-volume measurements, as described below, the conductance catheter was inserted in the LA through a purse-string suture at the base of the LAA. The conductance catheter was positioned along the long axis of the LA, and the tip was directed toward the orifice of the right PVs. The conductance catheter measured online atrial pressure and atrial chamber conductance by using dual-field technology with 10 electrodes set $4 \mathrm{~mm}$ apart.

Data acquisition. The RA and LA pressure-volume relationships were acquired sequentially throughout the study. Baseline data were recorded during steady-state conditions. For each data acquisition run, an electrocardiogram, heart rate, aortic pressure, superior and inferior vena caval flows, atrial pressure, and atrial conductance signals were acquired at $200 \mathrm{~Hz}$ and processed with custom-designed computer software. The respirator was held at end-expiration during data collection (10-15 seconds) to minimize the effects of intrathoracic pressure variation. After steady-state data were obtained (lasting 3-5 heart beats), the inferior vena cava was slowly and progressively occluded to generate atrial pressure-volume loops over a wide physiologic range of filling pressures. Data acquisition runs were repeated in triplicate; all runs containing 
premature ventricular contractions were excluded from analysis. Sufficient time was allowed between runs for hemodynamic stabilization (2-4 minutes)

Data analysis. The atrial elastance (contractility) was assessed by using the RA or LA end-systolic pressure-volume relationship, as previously described. ${ }^{22}$ Briefly, atrial end-systolic pressure (APA-ES) and volume (AVolA-ES) points were determined for each cardiac cycle during preload reduction, and by means of least-squares linear regression, a straight line was fitted to the following equation ${ }^{23}: A P A-E S=E A-E S \bullet(A-V o l A-E S-V o)$, where EA-ES (in millimeters of mercury per milliliter) and V0 (in milliliters) are the slope (atrial chamber elastance) and volume-axis intercept, respectively. Static atrial stiffness was defined as the slope of the RA or LA end-diastolic pressure-volume relationship. Atrial end-diastolic pressure (APA-ED) and volume (A-VolA-ED) points were determined at the time of maximum atrial volume for each cardiac cycle during preload reduction. By means of least-squares linear regression, a straight line was fitted to the following equation: $A P A-E D=A$ Stiffness $\bullet(A-V o l A-E D-V A-E D)$, where atrial (A) stiffness (in milliliters per millimeters of mercury) and VA-ED (in milliliters) are the slopes and atrial diastolic equilibrium volume, respectively.

\section{Histologic and Microscopic Analysis}

The excised heart en bloc was grossly examined for any evidence of intra-atrial thrombus formation, PV stenosis, or thrombosis. The heart was then immediately incubated at room temperature for 45 minutes in $1 \%$ 2,3,5-triphenyl-tetrazolium chloride solution. Each bipolar RF lesion was then sectioned $5 \mathrm{~mm}$ apart, perpendicular to the long axis of the ablation line. The sections were then fixed in formalin, molded in paraffin, and sectioned and stained with hematoxylin and eosin and Masson's trichrome stains. Each section was examined under the microscope to assess the lesion width, depth, and transmurality.

\section{Statistical Analysis}

All data are reported as means \pm standard deviation. Hemodynamic data obtained during stated-state recordings are reported as the average of 3 consecutive beats. Data were compared between preablation, postablation, and 30-day postoperative time points by using repeated-measures analysis of variance with 1 factor (group = sham vs maze). All statistical analyses were performed with SigmaStat 2.03 software (SPSS, Inc, Chicago, Ill).

\section{RESULTS \\ Operative Results}

All animals survived the operation. There were no postoperative cardiac arrhythmias, and each animal was in sinus rhythm after the initial operation and at the time of death. There were no gross neurologic complications. Postopera- tive MRI revealed no mitral or tricuspid valve insufficiency, and the coronary arteries remained patent in all 6 animals.

Acutely, there was electrical isolation of the LAA and right and left PVs in all 6 animals in the maze group, as documented by pacing. This was repeated at 30 days after the Cox maze procedure, which also revealed electrical isolation in all animals of both PVs and the LAA. Attempts to induce $\mathrm{AF}$ at 30 days were unsuccessful in all 6 animals in the maze group. AF was able to be induced in all 6 animals in the sham group at 30 days.

Animals uniformly gained significant weight during the 30-day study period. MRI-adjusted atrial and ventricular volumes were therefore body surface area (BSA) adjusted.

\section{Atrial Function Data}

Cardiac MRI data. There was no significant difference between the preoperative and 30-day postoperative LV ejection fraction, BSA-adjusted LV end-diastolic and endsystolic volumes, LVSV, and left ventricular ejection fraction for either the sham or the maze group (Table 1). However, both groups had a statistically significant increase in all BSA-adjusted LA volumes at various time points in the LA volume curves during the cardiac cycle (Table 2) at 30 days after the operation. Interestingly, there was no statistical difference in the changes in LA volumes between the maze and sham groups (Table 2).

The reservoir, conduit, and booster pump functional parameters for the LA are summarized in Table 2. There was a trend toward a reduction in the reservoir function parameter $\mathrm{LA}_{\mathrm{PTE}}$ at 30 days in the sham group $(P=.061)$ and a significant reduction in $\mathrm{LA}_{\mathrm{PTE}}$ at 30 days in the maze group $(P=.028)$. The difference in the reduction of $\mathrm{LA}_{\mathrm{PTE}}$ at 30 days between the sham and maze groups, however, was not significant $(P=.981)$. There was also a trend toward a reduction in the reservoir function parameter $\mathrm{LA}_{\mathrm{EI}}$ at 30 days in the sham $(P=.082)$ and maze $(P=.054)$ groups, but there was no difference between the groups $(P=.772)$.

None of the LA conduit functional parameters had any significant difference between the mean preoperative and 30-day postoperative values in either group. On the other hand, 2 of

TABLE 1. Preoperative versus 30-day postoperative left ventricular volumes and ejection fraction

\begin{tabular}{|c|c|c|c|c|c|c|c|}
\hline Parameters & $\begin{array}{c}\text { Sham group, } \\
\text { pre }(n=6)\end{array}$ & $\begin{array}{c}\text { Sham group, } \\
\text { post }(\mathrm{n}=6)\end{array}$ & $\begin{array}{c}P \\
\text { value* }^{*} \\
\end{array}$ & $\begin{array}{c}\text { Maze group, } \\
\text { pre }(n=6)\end{array}$ & $\begin{array}{c}\text { Maze group, } \\
\text { post }(n=6)\end{array}$ & $\begin{array}{c}P \\
\text { value } \dagger\end{array}$ & $\begin{array}{c}P \\
\text { value } \ddagger\end{array}$ \\
\hline Weight (kg) & $68.0 \pm 7.0$ & $97.2 \pm 11.0$ & $<.001$ & $65.5 \pm 6.4$ & $96.7 \pm 14.8$ & $<.001$ & .780 \\
\hline BSA & $1.40 \pm 0.09$ & $1.76 \pm 0.13$ & $<.001$ & $1.37 \pm 0.08$ & $1.75 \pm 0.17$ & $<.001$ & .663 \\
\hline LVEDV (mL) & $68.9 \pm 17.8$ & $71.9 \pm 8.4$ & .480 & $73.7 \pm 18.4$ & $78.3 \pm 18.8$ & .480 & .491 \\
\hline LVESV (mL) & $39.3 \pm 18.3$ & $35.8 \pm 10.9$ & .549 & $39.0 \pm 17.2$ & $46.8 \pm 16.9$ & .549 & .551 \\
\hline LVSV (mL) & $29.5 \pm 8.1$ & $36.1 \pm 8.9$ & .552 & $34.7 \pm 2.6$ & $31.5 \pm 7.0$ & .552 & .922 \\
\hline LVEF (\%) & $44.9 \pm 14.7$ & $50.6 \pm 12.4$ & .550 & $49.6 \pm 12.3$ & $41.0 \pm 8.7$ & .550 & .721 \\
\hline
\end{tabular}

Body surface area was calculated by using the following formula: $B S A=0.097 \times(k g$ body weight $) 0.633$. Pre, Preoperative; Post, postoperative; $B S A$, body surface area; $L V E D V$, left ventricular end-diastolic volume; $L V E S V$, left ventricular end-systolic volume; $L V S V$, left ventricular stroke volume; $L V E F$, left ventricular ejection fraction. *Between the preoperative and postoperative and sham groups. $\dagger$ Between the preoperative and postoperative maze groups. $\ddagger$ Between the sham and maze groups. 
TABLE 2. Preoperative versus 30-day postoperative LA volumes and functional parameters

\begin{tabular}{|c|c|c|c|c|c|c|c|}
\hline Parameters & $\begin{array}{c}\text { Sham group, } \\
\text { pre }(n=6)\end{array}$ & $\begin{array}{c}\text { Sham group, } \\
\text { post }(\mathrm{n}=6)\end{array}$ & $\begin{array}{c}P \\
\text { value* }^{*}\end{array}$ & $\begin{array}{c}\text { Maze group } \\
\text { pre }(n=6)\end{array}$ & $\begin{array}{l}\text { Maze group } \\
\text { post }(n=6)\end{array}$ & $\begin{array}{c}P \\
\text { value } \dagger\end{array}$ & $\begin{array}{c}P \\
\text { value } \ddagger \\
\end{array}$ \\
\hline $\mathrm{LA}_{\max }(\mathrm{mL})$ & $37.5 \pm 8.9$ & $57.3 \pm 10.6$ & .012 & $45.0 \pm 13.5$ & $67.9 \pm 17.3$ & .040 & .141 \\
\hline $\mathrm{LA}_{\text {rel max }}(\mathrm{mL})$ & $35.2 \pm 11.3$ & $54.2 \pm 11.1$ & .022 & $41.3 \pm 15.8$ & $63.6 \pm 16.0$ & .037 & .240 \\
\hline $\mathrm{LA}_{\min }(\mathrm{mL})$ & $27.1 \pm 9.8$ & $47.0 \pm 11.4$ & .007 & $31.3 \pm 14.0$ & $57.7 \pm 12.6$ & .009 & .223 \\
\hline $\mathrm{LA}_{\text {rel min }}(\mathrm{mL})$ & $32.8 \pm 10.2$ & $50.4 \pm 10.7$ & .022 & $38.8 \pm 15.9$ & $61.3 \pm 15.4$ & .034 & .194 \\
\hline $\mathrm{LA}_{\mathrm{CC}}(\mathrm{mL}) \S$ & $10.4 \pm 3.1$ & $10.4 \pm 4.4$ & .363 & $13.6 \pm 4.7$ & $10.2 \pm 5.8$ & .363 & .436 \\
\hline $\mathrm{LA}_{\mathrm{PTE}}(\%) \S$ & $29.1 \pm 10.6$ & $18.6 \pm 8.4$ & .061 & $33.0 \pm 15.3$ & $14.4 \pm 5.3$ & .028 & .981 \\
\hline $\mathrm{LA}_{\mathrm{EI}}(\%) \S$ & $43.7 \pm 22.5$ & $23.9 \pm 12.9$ & .082 & $56.7 \pm 40.1$ & $17.2 \pm 7.5$ & .054 & .772 \\
\hline $\operatorname{LA}_{P E}(\%) \|$ & $29.4 \pm 22.0$ & $32.5 \pm 11.8$ & .201 & $26.8 \pm 24.1$ & $42.5 \pm 10.9$ & .201 & .651 \\
\hline $\mathrm{LA}_{\mathrm{PEI}}(\%) \|$ & $9.7 \pm 8.4$ & $5.8 \pm 3.5$ & .213 & $10.5 \pm 12.4$ & $6.2 \pm 3.3$ & .213 & .862 \\
\hline $\mathrm{LA}_{\mathrm{AE}}(\%) \Phi$ & $53.7 \pm 29.6$ & $26.9 \pm 26.1$ & .101 & $50.9 \pm 24.7$ & $27.8 \pm 17.1$ & .113 & .937 \\
\hline $\mathrm{LA}_{\mathrm{AEI}}(\%)$ ฯ & $17.6 \pm 10.3$ & $7.5 \pm 7.7$ & .032 & $19.8 \pm 11.6$ & $5.2 \pm 4.4$ & .026 & .992 \\
\hline $\operatorname{LA}_{\mathrm{EF}}(\%) \Phi$ & $21.3 \pm 9.0$ & $12.8 \pm 6.4$ & .038 & $22.5 \pm 9.8$ & $8.1 \pm 3.0$ & .021 & .630 \\
\hline LARV (mL) & $4.7 \pm 2.9$ & $6.9 \pm 1.3$ & .251 & $6.2 \pm 3.1$ & $6.6 \pm 2.3$ & .251 & .539 \\
\hline LACV (mL) & $16.8 \pm 7.7$ & $22.0 \pm 8.9$ & .366 & $18.6 \pm 6.2$ & $19.0 \pm 5.1$ & .366 & .819 \\
\hline LABPV (mL) & $8.0 \pm 3.9$ & $7.2 \pm 3.8$ & .171 & $10.0 \pm 5.2$ & $5.9 \pm 3.7$ & .171 & .861 \\
\hline
\end{tabular}

Pre, Preoperative; Post, postoperative; $L A$, left atrial; $L A_{\text {max }}$, maximal left atrial volume; $L A_{\text {rel max }}$, relative maximal left atrial volume; $L A_{\text {min }}$, minimum left atrial volume; $L A_{\text {rel min }}$, relative minimal left atrial volume; $L A_{C C}$, left atrial volume change; $L A_{P T E}$, left atrial percentage total emptying; $L A_{E I}$, left atrial expansion index; $L A_{P E}$, left atrial passive percentage of total emptying; $L A_{P E I}$, left atrial passive emptying index; $L A_{A E}$, left atrial active emptying percentage of total emptying; $L A_{A E I}$, left atrial active emptying index; $L A_{E F}$, left atrial active ejection fraction; $L A R V$, left atrial reservoir volume; $L A C V$, left atrial conduit volume; $L A B P V$, left atrial booster pump volume. *Between the preoperative and postoperative sham groups. $\nmid$ Between the preoperative and postoperative maze groups. $\ddagger$ Between the sham and maze groups. $\S$ Reservoir functional parameters. $\|$ Conduit functional parameters. ๑Booster pump functional parameters.

the LA booster pump functional parameters, $\mathrm{LA}_{\mathrm{AEI}}$ and $\mathrm{LA} \mathrm{EF}$, significantly decreased at 30 days in both the sham and maze groups (Table 2). There were no differences between the sham and maze groups for $\mathrm{LA}_{\mathrm{AEI}}$ and $\mathrm{LA} \mathrm{AF}_{\mathrm{EF}}$.

The preoperative versus 30-day postoperative BSA-adjusted reservoir, conduit, and booster pump volumes of the LA for the sham and maze groups are summarized in Table 2 . There were no statistically significant differences between the preoperative and 30-day postoperative reservoir, conduit, or booster pump volumes. There were also no differences in these volumes between the maze and sham groups.

The preoperative and 30-day postoperative percentage contribution of the LA reservoir, conduit, and booster pump volumes to LV filling is shown in Figure 2 for the sham and maze groups. Both groups had a reduction in the booster pump volume contribution to LV filling, a small increase in the conduit volume contribution to LV filling, and a minimal increase in the reservoir volume contribution to LV filling. None of these findings were statistically significant, and there were no significant differences between the sham and maze groups (Figure 2).

In contrast to the above findings, the Cox maze procedure had a significant effect on the regional LA wall motion. All 4 segmental LA walls (anterior, posterior, medial, and lateral wall segments) evaluated had significant reductions in shortening between atrial systole and diastole in the maze group (Figure 3). On the contrary, the reduction in LA wall shortening at 30 days postoperatively in the sham group was not significant. The difference between the sham and maze groups in the reduction in the percentage of wall shortening after the operation was statistically significant for the medial $(P=.030)$ and lateral $(P=.032)$ LA wall segments (Figure 3).

Conductance catheter data. Various conductance catheter-derived hemodynamic values for the maze group were obtained. There was no difference in the immediate preablation and postablation heart rates ( $75 \pm 18$ vs $77 \pm 20$ beats/ $\min , P=.333$ ). The heart rate at the 30 -day postoperative conductance catheter measurements was $125 \pm 24$ beats/ min, which was significantly higher than during the initial operation $(P<.001)$. The aortic pressure did not change throughout the preablation period, immediately after ablation, and during the 30-day postoperative period (54 \pm 6 , $53 \pm 9$, and $54 \pm 8 \mathrm{~mm} \mathrm{Hg} ; P=.856$ ). Similarly, there was no difference in the preablation, immediate postablation, and 30-day postoperative relative LVSV $(37 \pm 16$, $33 \pm 15$, and $35 \pm 18 \mathrm{~mL} ; P=.126)$. There was no difference in the relative cardiac output between the preablation and immediate postablation periods $(2.6 \pm 1.0$ vs $2.4 \pm$ $1.0 \mathrm{~L} / \mathrm{min}, P=.219$ ). However, the 30 -day postoperative cardiac output was significantly higher when compared with that before and immediately after ablation $(4.0 \pm 1.4$ $\mathrm{L} / \mathrm{min}, P=.04$ and .038 ).

There was no significant difference between the preablation and immediate postablation mean LA pressures $(9.6$ \pm 1.8 vs $9.5 \pm 2.2 \mathrm{~mm} \mathrm{Hg}, P=.742$ ). There was no difference in the relative maximal mean LA volume immediately after ablation ( $34 \pm 4$ vs $31 \pm 2 \mathrm{~mL}, P=.084)$. The mean RA pressure did not change significantly during the 


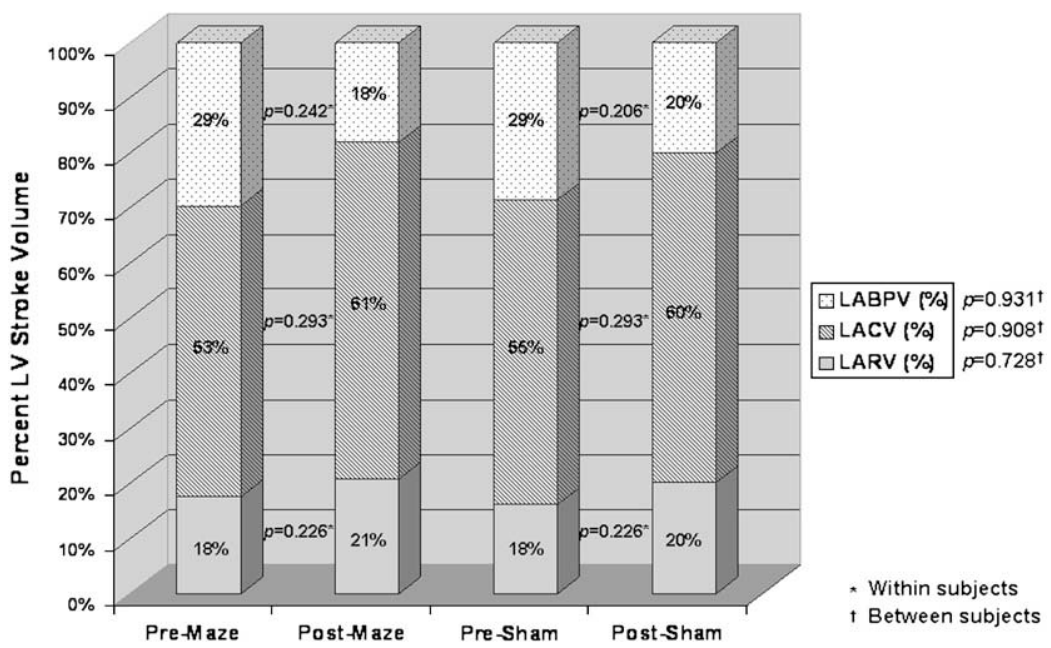

FIGURE 2. Preoperative versus 30-day postoperative left atrial contribution to left ventricular filling. $L A B P V$, Percentage contribution of left atrial booster pump volume to left ventricular stroke volume; $L A C V$, percentage contribution of left atrial conduit volume to left ventricular stroke volume; $L A R V$, percentage contribution of left atrial reservoir volume to left ventricular stroke volume; $L V$, left ventricular.

preablation, immediate postablation, and 30-day postoperative periods $(9.4 \pm 1.4,7.0 \pm 1.4$, and $8.7 \pm 2.9 \mathrm{~mm} \mathrm{Hg}$; $P=.263$ ). There was also no significant change in the relative maximal mean RA volume during the same time periods $(33 \pm 8,33 \pm 7$, and $38 \pm 5 \mathrm{~mL} ; P=.271)$.

The LA and RA elastance, as measured by the end-systolic pressure-volume relationship, did not change after the ablations or at 30 days postoperatively (Table 3 ). The LA stiffness, as measured by the end-diastolic pressure-volume relationship, increased significantly immediately after the ablations. The RA stiffness, however, did not change immediately after the ablations or at 30 days postoperatively.

\section{Histology}

There was no gross evidence of intra-atrial thrombus formation or stricture. Ablation lines on atrial tissue appeared as discrete, linear, and pale lesions. A total of 257 samples were examined from the 6 animals in the maze group. All lesions were transmural. The mean lesion width was $2.2 \pm 1.1 \mathrm{~mm}$, and the mean lesion depth was $5.3 \pm 3.0 \mathrm{~mm}$.

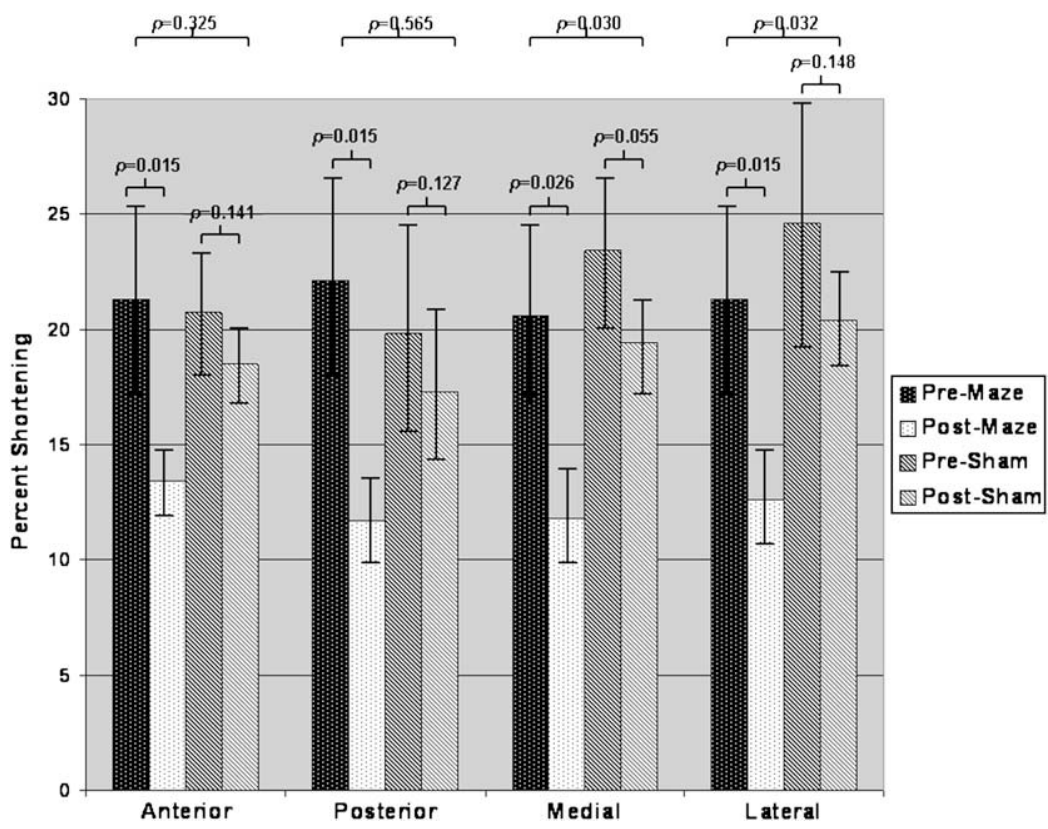

FIGURE 3. Preoperative versus 30-day postoperative regional left atrial wall motion. 
TABLE 3. Atrial elastance (contractility) and stiffness

\begin{tabular}{lcccc}
\hline & $\begin{array}{c}\text { Before the } \\
\text { maze } \\
\text { procedure } \\
(\mathbf{n}=\mathbf{6})\end{array}$ & $\begin{array}{c}\text { After the } \\
\text { maze } \\
\text { procedure } \\
(\mathbf{n}=\mathbf{6})\end{array}$ & $\begin{array}{c}\mathbf{3 0} \text { d After } \\
\text { the maze } \\
\text { procedure } \\
(\mathbf{n}=\mathbf{6})\end{array}$ & $\boldsymbol{P}$ value \\
\hline Parameters & $1.7 \pm 0.6$ & $1.9 \pm 1.1$ & - & .746 \\
$\mathrm{LA}_{\mathrm{ESPVR}}$ & $1.6 \pm 0.6$ & $1.4 \pm 0.4$ & $1.8 \pm 1.0$ & .771 \\
$\mathrm{RA}_{\mathrm{ESPVR}}$ & $1.1 \pm 0.3$ & $2.0 \pm 1.0$ & - & .049 \\
$\mathrm{LA}_{\mathrm{EDPVR}}$ & $1.8 \pm 0.7$ & $1.7 \pm 0.7$ & $2.0 \pm 1.5$ & .781 \\
$\mathrm{RA}_{\mathrm{EDPVR}}$ &
\end{tabular}

$L A_{E S P V R}$, Left atrial end-systolic pressure-volume relations; $R A_{E S P V R}$, right atrial endsystolic pressure-volume relations; $L A_{E D P V R}$, left atrial end-diastolic pressure-volume relations; $R A_{E D P V R}$, right atrial end-diastolic pressure-volume relations.

\section{DISCUSSION}

Although the Cox maze procedure has had excellent longterm success in eliminating $\mathrm{AF}$ and restoring sinus rhythm, its precise effects on LA function, geometry, and size remain poorly defined for several reasons.

First, atrial function and its wall motion are complex and difficult to quantify. Therefore published studies on atrial function are quite limited compared with those of the ventricles. It is, however, well established that the LA serves as a reservoir, conduit, and booster pump and is an important determinant of LV function and cardiac output.

Second, the methodological means available clinically to assess atrial function are limited. Conductance catheters and microsonometry can provide important load-independent indices of atrial function, but its invasive nature have prohibited them from clinical application. Echocardiography, on the other hand, is widely available but provides potentially inaccurate information on atrial function and volumes because it has limited resolution and also requires geometric assumptions on complex atrial anatomy. Recently, cardiac MRI has been applied to study atrial function, providing more accurate functional data with significantly higher-resolution image quality. However, it is still not able to calculate load-independent pressure-volume relationships.

There have been a number of studies on the effects of the Cox maze procedure on atrial function. ${ }^{15,24-30}$ Most of these studies have shown that the procedure negatively affects atrial function. Unfortunately, many of these studies involved patients who underwent combined operations that involved the Cox maze procedure and other procedures (ie, mitral valve repair and coronary artery bypass grafting) rather than stand-alone Cox maze procedures. Thus the changes seen in atrial function might not necessarily be solely attributed to the Cox maze procedure itself. Furthermore, the majority of these functional studies were performed with 2-dimensional echocardiography, which provided limited functional data, no atrial pressure-volume relationships, and no quantification of the atrial reservoir, conduit, and booster pump functions. These studies also did not provide any data on the effects of the procedure on regional LA wall motion. Moreover, they were performed in patients undergoing the Cox maze procedure with long-standing $\mathrm{AF}$ and likely abnormal atrial function and therefore do not provide information on the effects of the Cox maze lesion set on normal atrial function.

This study was designed to examine the detailed acute and chronic effects of the Cox maze procedure on LA volumes and reservoir, conduit, and booster pump functions and their contributions to LV filling, the dynamic contractility and stiffness of the atria, and LA segmental wall motion. The results of this study revealed that the Cox maze procedure had no effect on ventricular volumes and function at 30 days. LA volumes throughout the cardiac cycle were significantly higher 30 days after the Cox maze procedure. However, the same findings were observed in the sham group as well, with no statistical difference between the sham and maze groups in the MRI-derived LA volumes. Therefore the increase in LA volumes seen after surgical intervention is related to the median sternotomy and pericardiotomy and is not a result of the ablation lines of the Cox maze procedure. This emphasizes the importance of a control group that has been lacking in previous studies.

Surprisingly, the trend toward a reduction in the MRI-derived LA reservoir and booster pump functional parameters were also attributed to the median sternotomy and pericardiotomy and not the result of the Cox maze procedure because there was no statistical difference in the changes in the LA functional parameters between the maze and sham groups. Moreover, the postoperative changes in the percentage contribution of the LA reservoir, conduit, and booster pump volumes were not different between the 2 groups.

The only MRI-derived postoperative changes attributed to the Cox maze procedure were in segmental LA wall motion, specifically in the medial and lateral LA wall segments. Disruption of coordinated atrial activation and contraction from the ablations of the Cox maze procedure can explain the significant decrease in these wall segments.

The conductance catheter-derived results revealed that the Cox maze procedure had no significant effect on the intrinsic RA and LA wall elastance (contractility). The intrinsic atrial wall stiffness, however, was significantly higher after LA ablation but did not change for the RA. This is likely because the ablation sets for the LA are more extensive compared with the RA lesion set and result in the electrical isolation of a large amount of atrial tissue around the PVs (Figure 1).

There are several limitations to this study. A Cox maze procedure was performed on porcine hearts with normal atrial function. This is obviously quite different from the clinical setting, in which the procedure is typically performed in patients with long-standing AF and abnormal atrial function and possibly abnormal ventricular function caused by loss of synchronous atrioventricular contraction. 
Therefore, clinically, the Cox maze procedure might provide an improvement in atrial function postoperatively, depending on the patient, because the procedure restores normal sinus rhythm.

Another limitation of this study is the relatively small number of animals used in the 2 groups. This might have led to type 2 statistical errors. However, the use of a control group provided valuable new information, and it is unlikely that any significant changes would be missed with 6 animals in each group. Also, because of technical limitations, conductance catheter data were unable to be obtained for the LA at 30 days postoperatively.

In conclusion, the Cox maze procedure in this chronic porcine model had no statistically significant effect on atrial volumes or systolic function at 30 days measured either based on load-sensitive (MRI) or load-independent (conductance catheter) techniques. However, there was a significant immediate decrease in LA compliance after ablation. Whether this would be seen chronically would need to be investigated in a further study.

We thank Diane Toeniskotter and Naomi Still for their technical assistance.

\section{References}

1. Cox JL, Schuessler RB, D'Agostino HJ Jr, Stone CM, Chang BC, Cain ME, et al. The surgical treatment of atrial fibrillation. III. Development of a definitive surgical procedure. J Thorac Cardiovasc Surg. 1991;101:569-83.

2. Prasad SM, Maniar HS, Camillo CJ, Schuessler RB, Boineau JP, Sundt TM 3rd, et al. The Cox maze III procedure for atrial fibrillation: long-term efficacy in patients undergoing lone versus concomitant procedures. $J$ Thorac Cardiovasc Surg. 2003;126:1822-8.

3. Williams MR, Garrido M, Oz MC, Argenziano M. Alternative energy sources for surgical atrial ablation. J Card Surg. 2004;19:201-6.

4. Cummings JE, Pacifico A, Drago JL, Kilicaslan F, Natale A. Alternative energy sources for the ablation of arrhythmias. Pacing Clin Electrophysiol. 2005;28:434-43.

5. Prasad SM, Maniar HS, Diodato MD, Schuessler RB, Damiano RJ Jr. Physiological consequences of bipolar radiofrequency energy on the atria and pulmonary veins: a chronic animal study. Ann Thorac Surg. 2003;76:836-41.

6. Gaynor SL, Ishii Y, Diodato MD, Prasad SM, Barnett KM, Damiano NR, et al. Successful performance of Cox-Maze procedure on beating heart using bipolar radiofrequency ablation: a feasibility study in animals. Ann Thorac Surg. 2004; 78:1671-7.

7. Melby SJ, Gaynor SL, Lubahn JG, Lee AM, Rahgozar P, Caruthers SD, et al. Efficacy and safety of right and left atrial ablations on the beating heart with irrigated bipolar radiofrequency energy: a long-term animal study. J Thorac Cardiovasc Surg. 2006;132:853-60.

8. Gaynor SL, Diodato MD, Prasad SM, Ishii Y, Schuessler RB, Bailey MS, et al. A prospective, single-center clinical trial of a modified Cox maze procedure with bipolar radiofrequency ablation. J Thorac Cardiovasc Surg. 2004;128:535-42.

9. Mokadam NA, McCarthy PM, Gillinov AM, Ryan WH, Moon MR, Mack MJ, et al. A prospective multicenter trial of bipolar radiofrequency ablation for atrial fibrillation: early results. Ann Thorac Surg. 2004;78:1665-70.

10. Gaynor SL, Schuessler RB, Bailey MS, Ishii Y, Boineau JP, Gleva MJ, et al. Surgical treatment of atrial fibrillation: predictors of late recurrence. J Thorac Cardiovasc Surg. 2005;129:104-11.
11. Melby SJ, Kaiser SP, Bailey MS, Zierer A, Voeller RK, Lall SC, et al. Surgical treatment of atrial fibrillation with bipolar radiofrequency ablation: mid-term results in one hundred consecutive patients. J Cardiovasc Surg (Torino). 2006; 47:705-10.

12. Melby SJ, Zierer A, Bailey MS, Cox JL, Lawton JS, Munfakh N, et al. A new era in the surgical treatment of atrial fibrillation: the impact of ablation technology and lesion set on procedural efficacy. Ann Surg. 2006;244:583-92.

13. Lall SC, Melby SJ, Voeller RK, Zierer A, Bailey MS, Guthrie TJ, et al. The effect of ablation technology on surgical outcomes after the Cox-maze procedure: a propensity analysis. J Thorac Cardiovasc Surg. 2007;133:389-96.

14. Feinberg MS, Waggoner AD, Kater KM, Cox JL, Lindsay BD, Perez JE. Restoration of atrial function after the maze procedure for patients with atrial fibrillation. Assessment by Doppler echocardiography. Circulation. 1994;90(suppl 2): II285-92.

15. Feinberg MS, Waggoner AD, Kater KM, Cox JL, Perez JE. Echocardiographic automatic boundary detection to measure left atrial function after the maze procedure. J Am Soc Echocardiogr. 1995;8:139-48.

16. Bowman AW, Kovacs SJ. Left atrial conduit volume is generated by deviation from the constant-volume state of the left heart: a combined MRI-echocardiographic study. Am J Physiol Heart Circ Physiol. 2004;286:H2416-24.

17. Botnar RM, Stuber M, Danias PG, Kissinger KV, Manning WJ. Improved coronary artery definition with T2-weighted, free-breathing, three-dimensional coronary MRA. Circulation. 1999;99:3139-48.

18. Järvinen V, Kupari M, Hekali P, Poutanen VP. Assessment of left atrial volumes and phasic function using cine magnetic resonance imaging in normal subjects. Am J Cardiol. 1994;73:1135-8.

19. Spencer KT, Mor-Avi V, Gorcsan J 3rd, DeMaria AN, Kimball TR, Monaghan MJ, et al. Effects of aging on left atrial reservoir, conduit, and booster pump function: a multi-institution acoustic quantification study. Heart. 2001;85: 272-7.

20. Gaynor SL, Maniar HS, Prasad SM, Steendijk P, Moon MR. Reservoir and conduit function of right atrium: impact on right ventricular filling and cardiac output. Am J Physiol Heart Circ Physiol. 2005;288:H2140-5.

21. Steendijk P, Staal E, Jukema JW, Baan J. Hypertonic saline method accurately determines parallel conductance for dual-field conductance catheter. Am J Physiol Heart Circ Physiol. 2001;281:H755-63.

22. Gaynor SL, Maniar HS, Bloch JB, Steendijk P, Moon MR. Right atrial and ventricular adaptation to chronic right ventricular pressure overload. Circulation. 2005;112(suppl):I212-8.

23. Moon MR, DeAnda A, Castro LJ, Daughters GT 2nd, Ingels NB Jr, Miller DC. Effects of mechanical left ventricular support on right ventricular diastolic function. J Heart Lung Transplant. 1997;16:398-407.

24. Itoh T, Okamoto H, Nimi T, Morita S, Sawazaki M, Ogawa Y, et al. Left atrial function after Cox's maze operation concomitant with mitral valve operation. Ann Thorac Surg. 1995;60:354-60.

25. Albirini A, Scalia GM, Murray RD, Chung MK, McCarthy PM, Griffin BP, et al. Left and right atrial transport function after the Maze procedure for atrial fibrillation: an echocardiographic Doppler follow-up study. J Am Soc Echocardiogr. 1997; 10:937-45.

26. Jessurun ER, van Hemel NM, Kelder JC, Defauw JA, Brutel de la Riviere A, Ernst JM, et al. The effect of maze operations on atrial volume. Ann Thorac Surg. 2003;75:51-6.

27. Lonnerholm S, Blomstrom P, Nilsson L, Blomstrom-Lundqvist C. Atrial size and transport function after the Maze III procedure for paroxysmal atrial fibrillation. Ann Thorac Surg. 2002;73:107-11.

28. Yashima N, Nasu M, Kawazoe K, Hiramori K. Serial evaluation of atrial function by Doppler echocardiography after the maze procedure for chronic atrial fibrillation. Eur Heart J. 1997; 18:496-502.

29. Darpo B, Ryden L. Restoration of atrial function after the maze procedure. Eur Heart J. 1997;18:360-1.

30. Ueshima K, Hashimoto K, Chiba M, Nakamura M, Nasu M, Hiramori K, et al. Recovery of atrial function after combined treatment with surgical repair for organic heart disease and maze procedure for atrial fibrillation. J Thorac Cardiovasc Surg. 1997;113:214-5. 


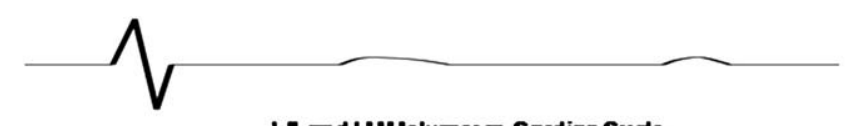

LA and LVVolumevs. Cardiac Cyde

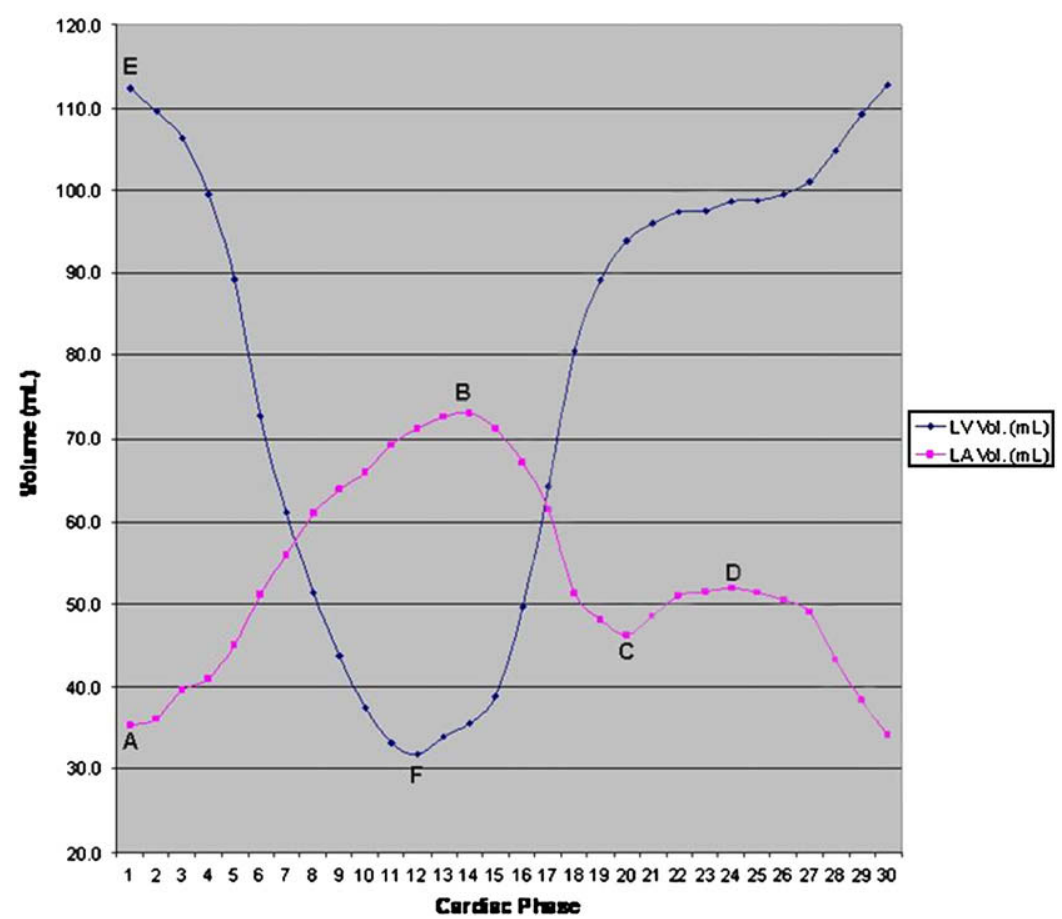

FIGURE E1. Left atrial $(L A)$ and left ventricular $(L V)$ volume versus cardiac cycle curves. The curve with $A, B, C$, and $D$ represents a normal left atrial volume curve. Point A, Minimal LA volume; point $B$, maximal LA volume; point $C$, relative minimal LA volume; point $D$, relative maximal LA volume. The curve with $E$ and $F$ represents a normal left ventricular volume curve. Point $E$, Left ventricular end-diastolic volume; point $F$, left ventricular end-systolic volume. Left ventricular stroke volume $=$ point $\mathrm{E}$ - point $\mathrm{F}$; left atrial reservoir volume $=$ point $\mathrm{B}$ - point $\mathrm{C}$; left atrial booster pump volume $=$ point $\mathrm{D}-$ point A; Left atrial conduit volume $=$ left ventricular stroke volume - left atrial reservoir volume - left atrial conduit volume . 


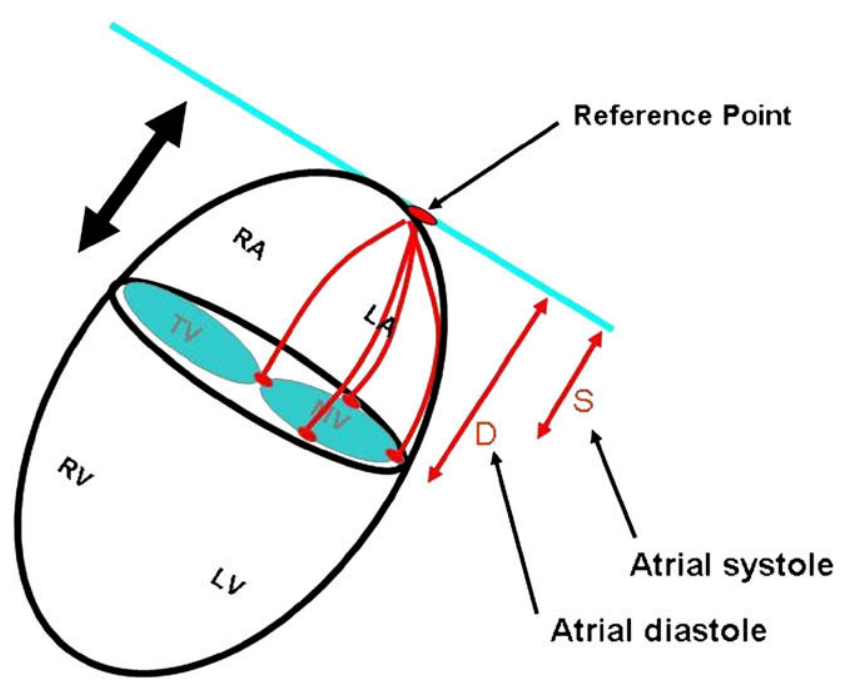

FIGURE E2. Regional assessment of left atrial function. The left atrium is divided into 4 segments: anterior, posterior, medial, and lateral. Percentage shortening of each segment during left atrial systole and diastole was measured. The reference point was stationary throughout the cardiac cycle. $R A$, Right atrium; $L A$, left atrium; $T V$, tricuspid valve; $M V$, mitral valve; $R V$, right ventricle; $L V$, left ventricle. 


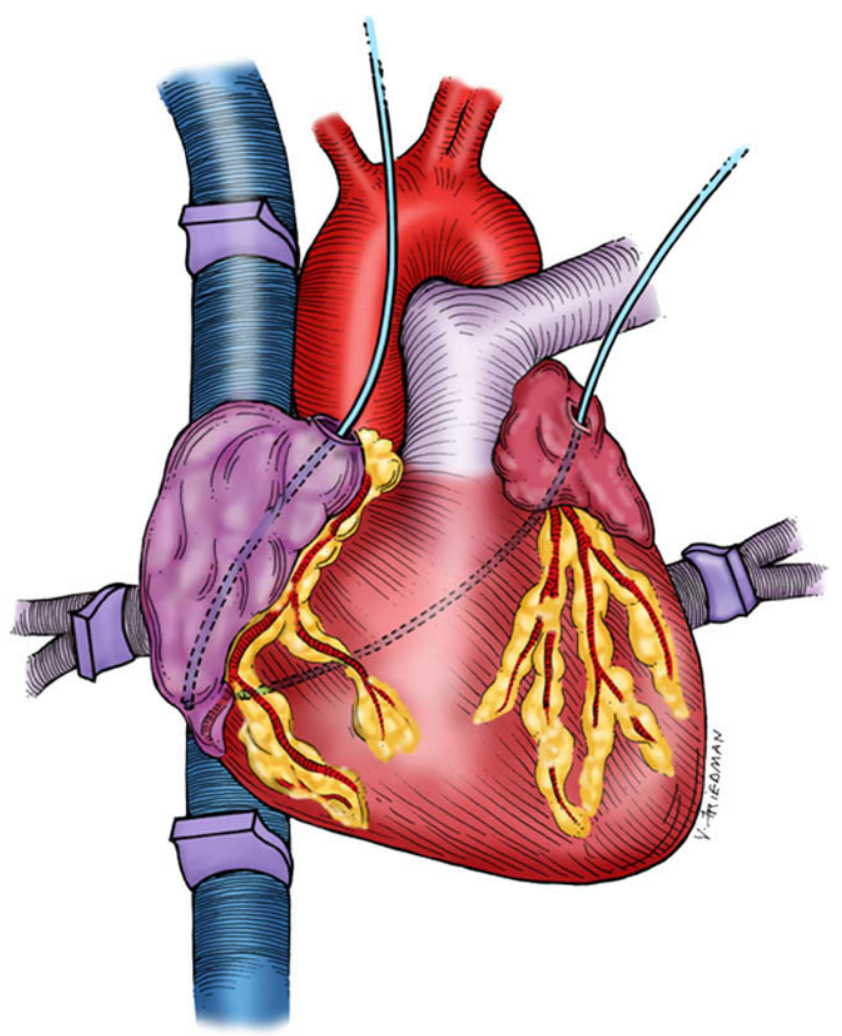

FIGURE E3. Conductance catheter placement in the right and left atria. Conductance catheters were inserted into both atria separately to measure pressure-volume relations. 